\title{
TEKNIK SABLON DENGAN LEM SEBAGAI ALTERNATIF MEMBUAT BAHAN AJAR BAGI GURU-GURU TK/RA DI CIMAHI BANDUNG
}

\author{
Mohamad Shindy, Yayah Rukiah, Enny Nurcahyawati \\ Program Studi Desain Komunikasi Visual \\ Fakultas Bahasa dan Seni, Universitas Indraprasta PGRI \\ shindy88.ms@gmail.com,ya2hrukiah@gmail.com,ennienurcahya@gmail.com
}

\begin{abstract}
Abstraks
Kegiatan pengabdian kepada masyarakat ini dilakukan di Kantor Kementerian Agama Kota Cimahi Bandung. yang menaungi sekolah-sekolah RA/TK se-Kota Cimahi. Kepala Kantor Kementerian Agama Kota Cimahi ingin memberikan pelatihan yang belum pernah dilakukan kepada guru-guru sekolah RA/TK. Pelatihan yang membutuhkan kreativitas dan inovasi baru bagi guru-guru RA/TK. Berdasarkan hal tersebut tim kami berinisiatif untuk membuat pelatihan mengenai teknik sablon tanpa menggunakan cat dan screen, melainkan dengan lem dan gambar yang diprint laser atau disebut juga dengan teknik transfer laser print. Hal ini dilakukan untuk menstimulus para guru agar bisa lebih kreatif dan dapat menjadi peluang usaha, karena teknik ini bisa digunakan ke semua media tidak hanya triplek dan kain keras yang kami contohkan. Kegiatan ini juga diharapkan mampu memberikan pengetahuan dan wawasan baru bagi para guru, serta dapat dipraktikkan langsung kepada murid-murid di sekolah masing-masing.
\end{abstract}

Kata kunci : teknik sablon, bahan ajar, print laser

\begin{abstract}
Community service activities are conducted in the Office of the Ministry of Religious City Cimahi Bandung. which oversees RA / TK schools in Cimahi City. Head Office of the Ministry of Religious Affairs Cimahi want to provide training that has never been done to school teachers RA / TK. Training that requires new creativity and innovation for RA / TK teachers. Based on that our team took the initiative to make training on screen printing techniques without the use of paint and screen, but with glue and laser-printed images or also called the laser print transfer technique. This is done to stimulate the teachers to be more creative and can be a business opportunity, because this technique can be used to all media not only plywood and hard fabric that we exemplify. This activity is also expected to provide new knowledge and insight for the teachers, and can be practiced directly to the students in each school.
\end{abstract}

Keywords : screen printing techniques, teaching materials, laser prints

\section{PENDAHULUAN}

Pendidikan mempunyai tahapan yang ditetapkan berdasarkan tingkat perkembangan peserta didik, tujuan yang akan dicapai, dan kemmapuan yang dikembangkan. Pendidikan juga memp- unyai kelompok layanan pendidikan, yang menyelenggarakan pendidikan pada jalur formal, non formal dan informal pada setiap jenjang dan jenis pendidikan. Taman Kanak-kanak (TK) adalah salah satu bentuk satuan pendidikan anak usia dini pada jalur 
pendidikan formal bagi anak usia 4 tahun sampai 6 tahun. Pada masa ini anak memasuki tahap praoperasional konkret dalam berpikir dari aktifitas belajar di TK.

Pada saat ini sikap egosentris pada anak semakin nyata, menurut Piaget dalam Sujiono (2010:26) anak mulai memiliki perspektif yang berbeda dengan orang lain yang berada di sekitarnya. Adapun pendidikan di TK ini adalah untuk memfasilitasi pertumbuhan dan perkembangan anak secara optimal dan menyeluruh sesuai dengan normanorma dan nilai-nilai kehidupannya, mellaui pendidikan TK ini diharapkan anak dapat mengemabngkan segenap potensi yang dimilikinya baik psikis maupun fisik yang meliputi moral, agama, sosial, emosional. Kognitif dan bahasa untuk siap memasuki pendidikan selanjutnya.

Peran pendidik sebenarnya sangat dibutuhkan dalam upaya mengembangkan potensi anak. Upaya pengembangan tersebut melalui kegiatan bermain sambil belajar, belajar seraya bermain, dengan demikian anak akan memiliki kesempatan untuk bereksplorasi, menemukan, mengekspresikan perasaan dan berkreasi. Masing-masing anak mempunyai modal kreativitas dalam dirinya, guru hanya perlu menyediakan sarana dan prasarana untuk menyalurkan seluruh potensi anak tersebut. Rangsangan dapat diberikan dengan cara memberikan kesempatan pada anak untuk menjadi kreatif. Biarkan anak dengan bebas melakukan, memegang, menggambar, membentuk maupun membuat dengan caranya sendiri.

Munculkan daya kreativitas anak dengan membiarkan anak menuangkan imajinasinya. Ketika anak mengembangkan keterampilan kreatif, maka anak tersebut juga dapat menghasilkan ide-ide yang inovatif dan jalan keluar dalam menyelesaikan masalah serta meningkat- kan kemampuan dalam mengingat sesuatu. Santrock dalam Yuliani (2010:6) menyatakan bahwa kreativitas adalah kemampuan untuk memikirkan sesuatu dengan cara-cara baru dengan tidak bisa serta melahirkan suatu solusi yang unik terhadap masalah-masalah yang dihadapi. Sedangkan Semiawan dalam Munandar (1995:5) mengatakan kreativitas adalah kemampuan untuk memberikan gagasan-gagasan baru dan menerapkannya dalam pemecahan masalah. Suatu cara yang dapat menyalakan percikan-percikan kreativitas anak usia dini adalah dengan membebaskan anak menuangkan pikirannya.

Kemampuan kognitif yang dapat dikembangkan melalui kegiatan bermain yaitu kemampuan mengenal, mengingat, berpikir konvergen, divergen, memberi penilaian. Kegiatan bermain dilakukan dengan mengamati dan mendengar. Mengamati dilakukan dengan melihat bentuk, warna, ukuran; melihat persamaan dan perbedaan bentuk, warna dan ukuran; menciptakan masalah berdasar pengenalannya tentang bentuk, warna, ukuran. Bahan dan peralatan yang dibutuhkan sebagaimana terdapat dalam Pedoman Penggunaan Alat Peraga Taman Kanak-kanak (Depdikbud, 1992): balok unit, papan pasak kecil, papan pasak berjenjang, papan tongkat, warna, menara, gelang bujur sangkar, balok ukur, papan hitung. Disamping itu juga bermacam benda yang ada di sekitar anak usia taman kanak-kanak.

Masa usia dini merupakan periode emas (Golden Age) bagi perkembangan anak untuk memperoleh pendidikan. Periode ini adalah tahun-tahun berharga bagi seorang anak untuk mengenali berbagai macam fakta dilingkungannya sebagai stimulasi terhadap perkembangan kepribadian, psikomotor kognitif maupun sosialnya. Periode emas ini 
merupakan periode kritis bagi anak, dimana perkembangan yang diperoleh pada periode ini sangat berpengaruh terhadap perkembangan periode berikutnya hingga masa dewasa. Sementara masa emas ini hanya datang sekali, sehingga apabila terlewat habislah peluangnya. Untuk itu pendidikan untuk usia dini dalam bentuk pemberian rangsangan-rangsangan (stimulasi) dari lingkungan terdekat sangat diperlukan untuk mengoptimalkan kemampuan anak.

Bermain sebagai bentuk kegiatan belajar di Pendidikan Anak Usia Dini/ Taman Kanak-kanak adalah bermain kreatif dan menyenangkan. Froebel dalam Audrey Curtis (1998) mengemukakan bahwa melalui bermain kreatif anak dapat mengembangkan serta mengintegrasikan semua kemampuannya. Anak lebih banyak belajar melalui bermain dan melakukan eksplorasi terhadap objek-objek dan pengalamannya karena anak dapat membangun pengetahuannya sendiri melalui interaksi sosial dengan orang dewasa pada saat mereka memahaminya dengan bahasa dan gerakan sehingga tumbuh menuju secara kognitif menuju berpikir verbal.

Satu hal yang tak kalah pentingnya adalah pendidikan agama sejak usia dini. Karena pendidikan agama berfungsi menanamkan keimanan kepada anak sebagai bekal kehidupan di masa depan. Keimanan adalah modal utama untuk mengembangkan kecerdasan spiritual (Spiritual Quotient), yang juga disebut sebagai salah satu ragam kecerdasan Majemuk (Multiple Intelligence). Kecerdasan spiritual tidak boleh dianggap remeh dalam kehidupan. Ia berfungsi sebagai life skill (kecakapan hidup) untuk membangun kehidupan yang berkualitas.

Perkembangan belajar anak memang perlu didukung tidak hanya dari segi peralatan saja, tetapi juga dari segi kesiapan pendidik. Guru adalah pusat pusaran kreativitas yang positif dan berkeinginan untuk mengarahkan anak didik menjadi lebih baik (Suwati, 2008:20), maka dari itu pentingnya seorang guru untuk mampu mentransfer ilmu dengan baik dan mudah dipahami oleh peserta didik.

Mengacu pada perkembangan kognitif anak-anak pada masa sekolah dasar memiliki pemikiran logis menggantikan pemikiran intuitif. Anak sudah mampu berpikir rasional dan melakukan aktivitas logis tertentu, walaupun masih terbatas pada objek konkret dan dalam situasi konkret (Soetjiningsih, 2012: 258), salah satunya adalah aktivitas dalam membuat suatu karya atau kerajinan tangan.

Kreativitas adalah hasil dari interaksi antara individu dan lingkungannya. Seseorang mempengaruhi dan dipengaruhi oleh lingkungan di mana ia berada, dengan demikian baik perubah di dalam individu maupun di dalam lingkungan dapat menunjang atau dapat menghambat upaya kreatif. Implikasinya ialah bahwa kemampuan kreatif dapat ditingkatkan melalui pendidikan (Utami, 2009: 12).

Berkenaan dengan hal tersebut, Kementerian Agama Kota Cimahi yang menaungi sekolah-sekolah RA/TK dan dengan Visi "TERWUJUDNYA MASYARAKAT INDONESIA YANG TAAT BERAGAMA, RUKUN, CERDAS, DAN SEJAHTERA LAHIR BATIN DALAM RANGKA MEWUJUDKAN INDONESIA YANG BERDAULAT, MANDIRI DAN BERKEPRIBADIAN BERLANDASKAN GOTONG ROYONG".

\section{Misi}

1. Meningkatkan pemahaman dan pengamalan ajaran agama 
2. Memantapkan kerukunan intra dan antar umat beragama

3. Menyediakan pelayanan kehidupan beragama yang merata dan berkualitas

4. Meningkatkan pemanfataan dan kualitas pengelolaan potensi ekonomi keagamaan

5. Mewujudkan penyelenggaraan ibadah haji dan umroh yng berkualitas dan akuntabel

6. Meningkatkan akses dan kualitas pendidikan umum berciri agama, pendidikan agama pada satuan pendidikan umum, dan pendidikan keagamaan

7. Mewujudkan tata kelola pemerintahan yang bersih, akuntabel, dan terpercaya

Kementerian Agama Kota Cimahi ingin memberikan pelatihan yang dapat menambah kreatifitas para guru dalam proses ngajar mengajar. Kami memberikan pelatihan teknik sablon dengan menggunakan lem dan image yang diprint laser dengan media transfer triplek dan kain keras.

Menurut Dameria (2008:42) cetak saring/screen printing adalah suatu cara mencetak dengan menekan tinta melalui celah/lubang sempit pada kain sutera (silk screen) sebagai acuan cetaknya. Setak saring sering disebut juga sablon atau juga "silk screen printing". Screen printing atau sablon merupakan teknik cetak yang banyak digunakan untuk permukaan yang tidak teratur seperti botol plastik, compact untuk kemasan kosmetik dan botol gelas.

Media yang dibuat penggabungan gambar atau objek dan kata. Dalam menentukan jenis huruf dan ukuran yang cocok, perlu memahami beberapa hal berikut: jenis huruf yang berbeda mempunyai ukuran yang berbeda walaupun menggunakan satuan ukuran yang sama (point) (Rustan, 2010:18). Dengan pelatihan ini guru-guru diharapkan dapat mentransfer ilmu yang didapat ke murid-murid dan juga dapat membuat bahan ajar sendiri yang lebih inovasi dan kreatif.

\section{METODE PELAKSANAAN}

Metode pelaksanaan yang digunakan melalui observasi terlebih dahulu, dan wawancara langsung dengan Kepala Kantor Kementerian Agama Kota Cimahi Bapak H. Cece Hidayat untuk menanyakan apa yang dibutuhkan oleh sekolah-sekolah RA/TK di Cimahi dan kami tim pengabdian akan berusaha untuk membantu menemukan solusi dan merealisasinya. Dengan adanya posisi dan fungsi kinerja dari setiap tim ini, menjadi layak untuk bisa menghadapi, merumuskan hingga menyelesaikan suatu persoalan yang dihadapi Kementerian Agama Kota Cimahi yang membawahi sekolah-sekolah RA/TK untuk memberikan pelatihan dan pengetahuan baru bagi guru-guru yang berhubungan dengan kreatifitas.

Anggota tim ini masing-masing memiliki andil tersendiri dalam melaksanakan kegiatan pengabdian masyarakat ini. Dalam proses pelatihan ini sebelumnya peralatan atau material disiapkan dari cetak image atau gambar dilakukan oleh ibu Yayah dibantu dengan pak Shindy dan ibu Enny.

Dalam proses pelaksanaan kegiatan pengabdian masyarakat ini masing-masing memiliki tugas yaitu memberikan penyuluhan dan penjelasan tentang proses atau tahapan untuk mentransfer image ke atas material. Pengarahan dan penjelasan materi disampaikan oleh ibu Yayah dengan menjelaskan bahan apa saja yang digunakan untuk pelatihan teknik transfer, sampai tahapan dari proses 
penempelan dan pengangkatan kertas, sedangkan ibu Enny dan pak Shindy mendampingi dalam proses penyuluhan dan pelatihan. Untuk image atau gambar yang digunakan dalam pelatihan ini kami sesuaikan dengan sekolah RA yaitu nama-nama Allah atau Asmaul Husna yang ditransfer ke media triplek, sedangkan untuk gambar siluet ditransfer ke media kain korea atau kain keras, kami memilih gambar siluet untuk dan kain keras agar hasilnya seperti lukisan. Pertama kami menjelaskan peralatan dan perlengkapan yang dibutuhkan, di antaranya :

\section{Lem Fox}

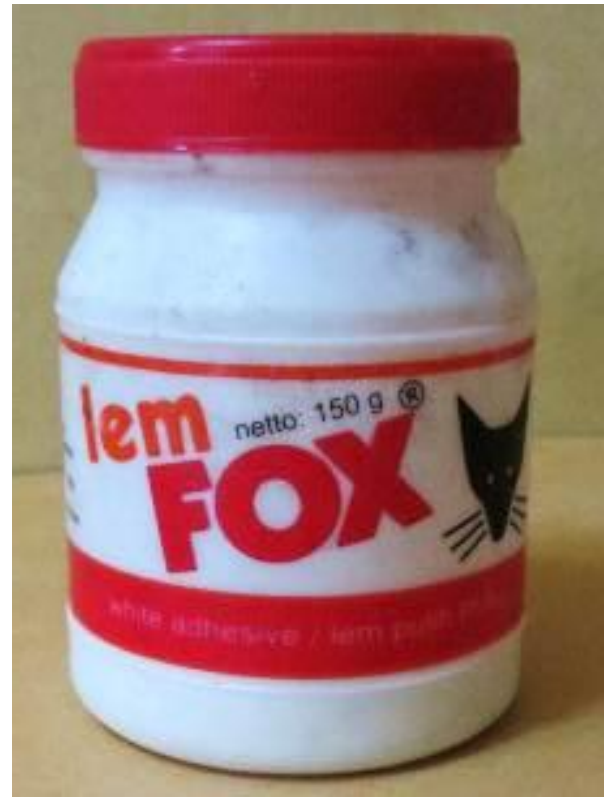

Gambar 1. Lem Fox
2. Lem dan varnish Golden

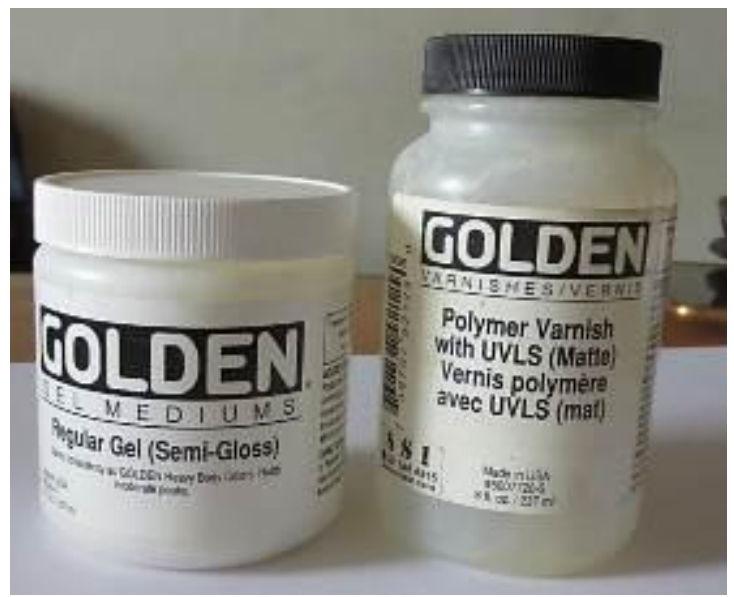

Gambar 2. Lem dan Varnish Golden

3. Image atau gambar yang diprint laser

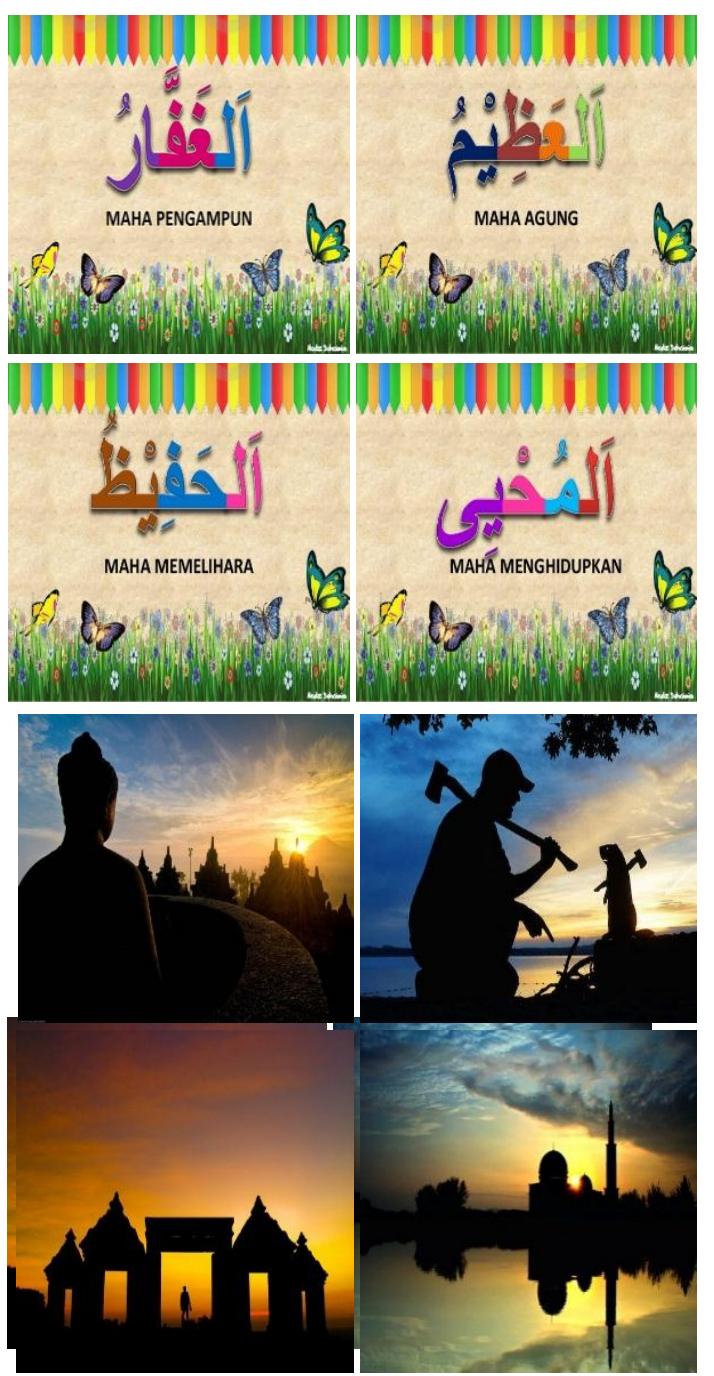

Gambar 3. Gambar yang ingin di transfer 
4. Media Transfer

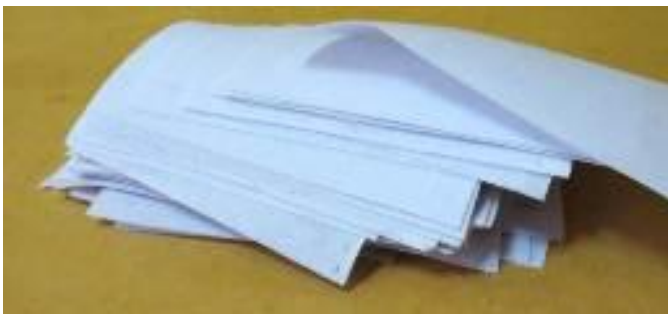

Gambar 4. Media transfer Kain Korea (kain keras)

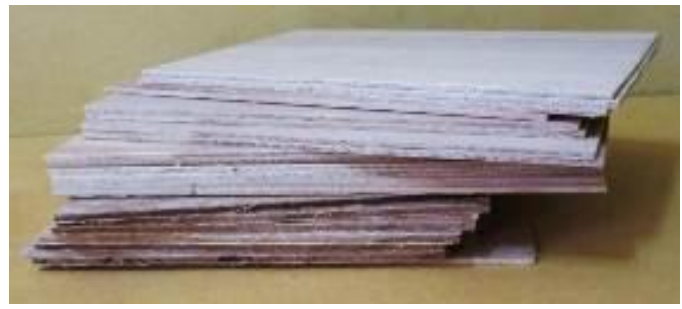

Gambar 5. Media transfer Triplek

5. Wadah dan Kain Perca

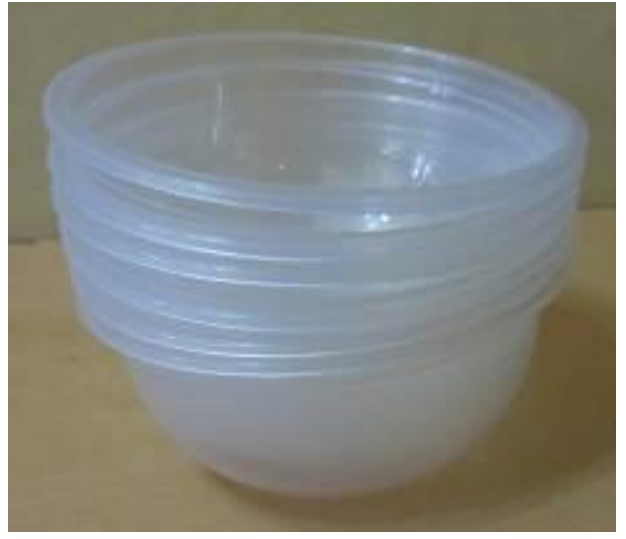

Gambar 6. Wadah

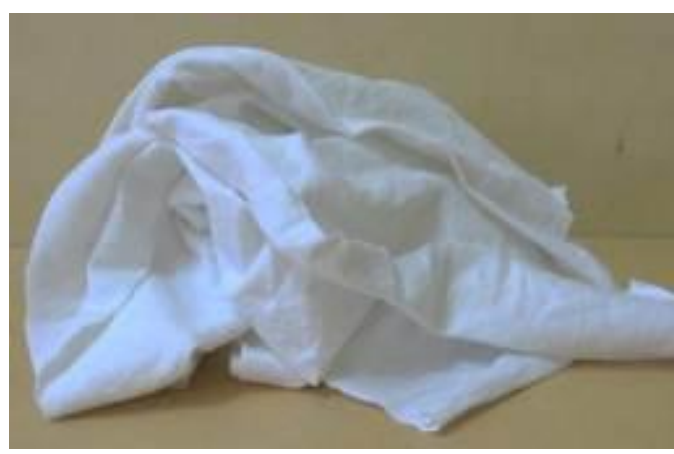

Gambar 7. Kain perca
6. Kuas dan Pilox Clear

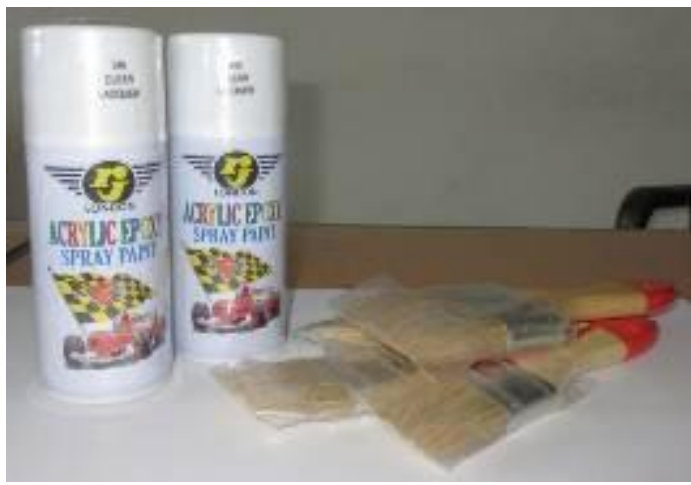

Gambar 8. Pilox Clear dan Kuas

7. Melamine Lack

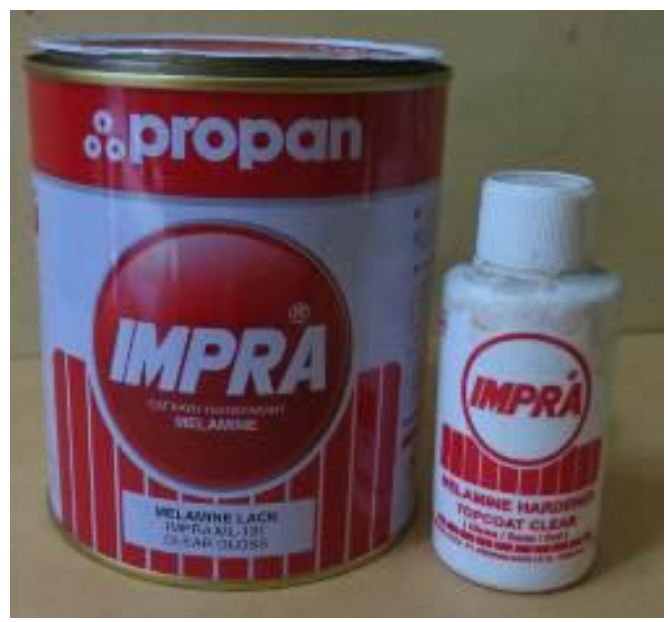

Gambar 9. Melamine lack dan pengeras

\section{HASIL DAN PEMBAHASAN}

Pengabdian masyarakat ini diharapkan dapat membantu pihak mitra yaitu Kementerian Agama Kota Cimahi yang dalam hal ini membawahi sekolahsekolah RA/TK yang ada di seluruh wilayah Cimahi Bandung untuk memberikan pengetahuan yang baru dalam teknik sablon dengan menggunakan lem dengan image yang diprint laser, dan juga melalui pelatihan ini peserta dapat mengajarkan dan mentransfer kembali kepada muridmurid teknik sablon transfer laser print ini.

Pelatihan dihadiri oleh perwakilan guru-guru RA/TK se-Kota Cimahi Bandung yang berjumlah 73 guru. 
Pelatihan ini diawali dengan kami sebagai tim abdimas memberikan penyuluhan, penjelasan kepada peserta mengenai teknik transfer laser print, para guru terlihat antusias dalam memperhati-kan penjelasan kami. Untuk pelatihan ini kami memberikan alternatif dalam penggunaan lem dan varnish yang mudah didapat dan terjangkau, agar peserta dapat terus mempraktikkan ilmu yang diberikan dari pelatihan ini.

Pelaksanaan kegiatan Pengabdian kepada Masyarakat dalam bentuk penyuluhan dan pelatihan teknik sablon dengan menggunakan lem sebagai alternatif membuat bahan ajar dengan teknik transfer laser print bagi guru-guru RA/TK se-Kota Cimahi Bandung telah selesai kami laksanakan sesuai target. Sambutan dari guru-guru RA/TK sangat baik dan antusias untuk pelatihan ini, karena pelatihan ini sesuatu yang belum mereka ketahui sebelumnya. Para peserta yang merupakan perwakilan dari sekolah RA/TK se-Kota Cimahi Bandung ingin kami mengadakan pelatihan teknik ini langsung ke sekolah masing-masing dilain waktu, sedangkan pihak Kementerian Agama Kota Cimahi menginginkan kami melakukan pengabdian masyarakat kembali dengan pelatihan yang berbeda yang disesuaikan dengan kebutuhan guru-guru RA/TK yang ada.

Sebelum kegiatan abdimas ini dilaksanakan, para guru sama sekali belum mengenal teknik laser print seperti apa, namun setelah kami berikan penyuluhan, penjelasan dan pelatihan langsung, alhamdulillah mereka mengerti dan dapat melakukan percobaan membuat contoh dasar pembuatan bahan ajar secara sederhana dapat dilakukan dengan cukup baik, ke depannya tinggal mereka mengembangkan untuk ukuran yang lebih besar atau dengan menggunakan media yang mereka inginkan dan sesuaikan dengan kebutuhan.

Pelaksanaan kegiatan pengabdian masyarakat yang dilaksanakan oleh tim dosen DKV Universitas Indraprasta PGRI pada kesempatan kali ini telah berjalan dengan baik dan kondusif, bahkan para guru mendapatkan wawasan baru untuk mengembangkan kreativitas yang inovatif bagi mereka untuk membuat sablon dengan menggunakan screen dan cat, atau bila ingin sablon dengan media kaos bisa menggunakan kertas khusus (special paper) yang setelah diprint hanya ditekan dan proses pemanasan menggunakan seterika listrik ke bahan kaos dan gambar tertransfer ke media. Untuk pengabdian masyarakat selanjutnya kami menyerahkan kepada pihak Kementerian Agama Kota Cimahi yang menggoordinir sekolah-sekolah RA/TK di Kota Cimahi karena banyaknya permintaan kepada kami agar melakukan pengabdian masyarakat langsung ke sekolah-sekolah. Kami akan berusaha memenuhi permintaan itu agar kerjasama sama dan silahturahmi tetap terjalin dengan baik antara Kementerian Agama Kota Cimahi dengan Universitas Indraprasta PGRI.

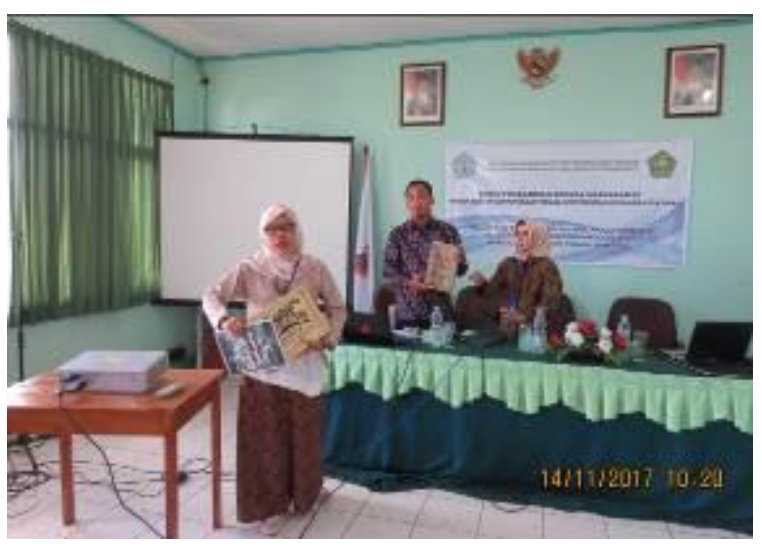

Gambar 10. Memperlihatkan karya dengan lem 


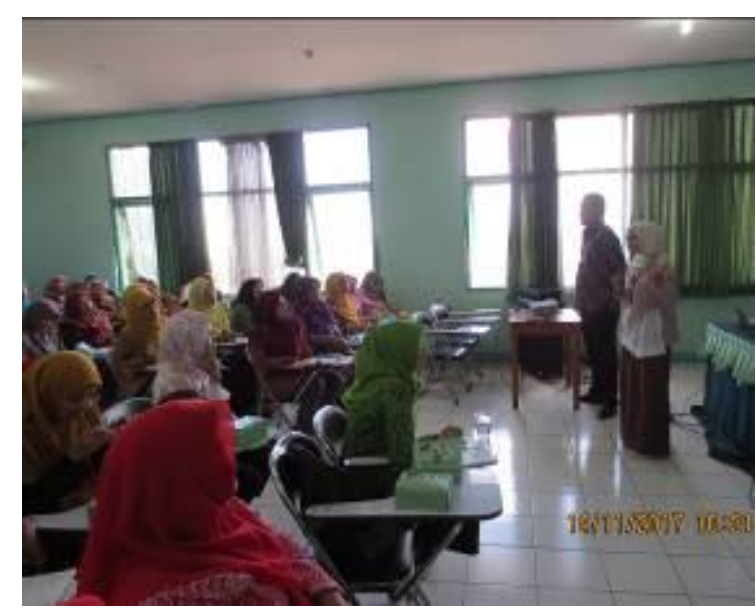

Gambar 11. Menjelaskan peralatan yang dibutuhkan

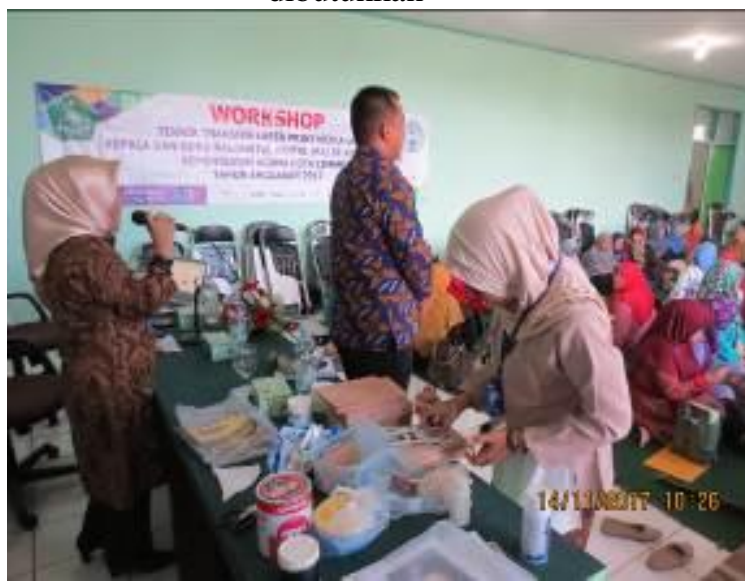

Gambar 12. Mempersiapkan peralatan untuk

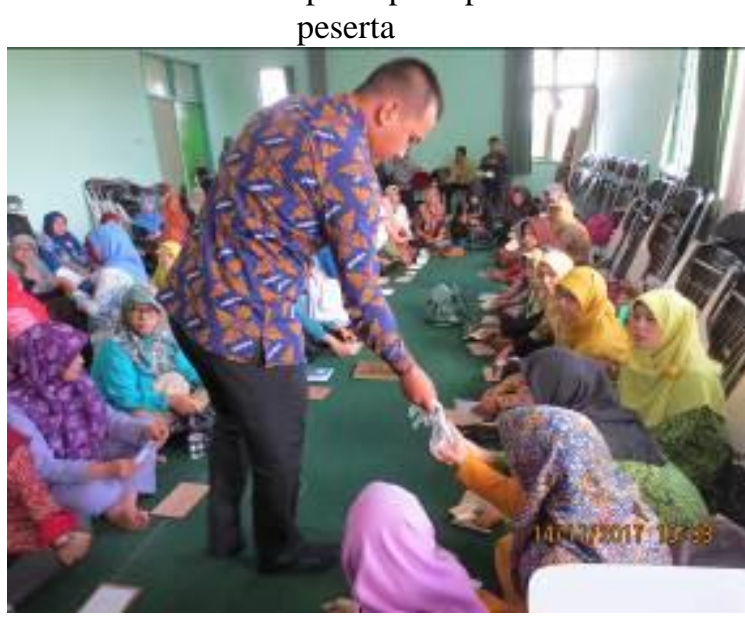

Gambar 13. Membagikan kain perca

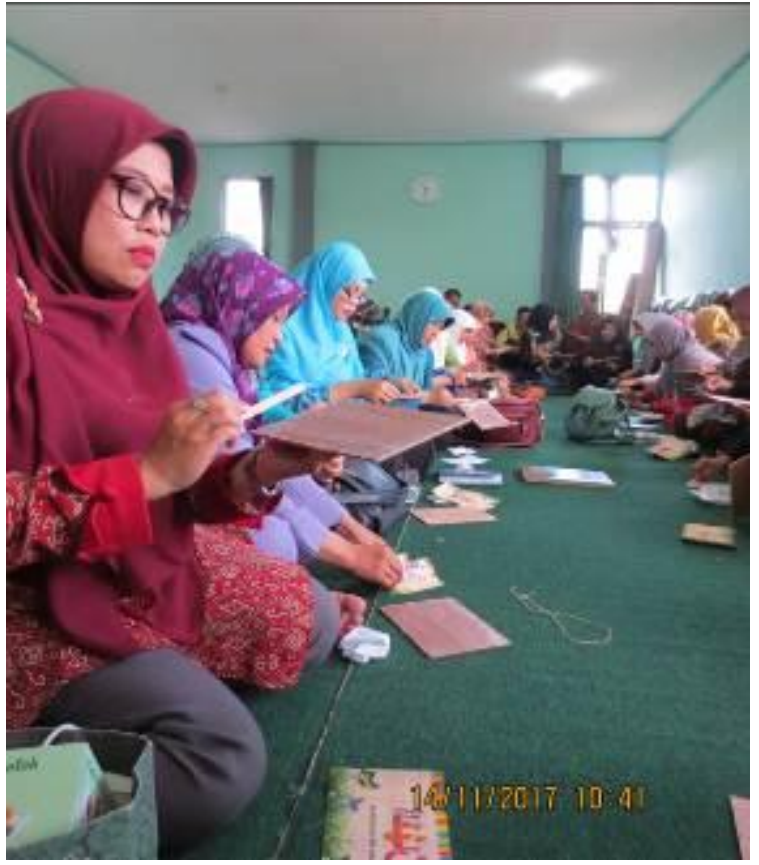

Gambar 14. Proses pengeleman dan penempelan

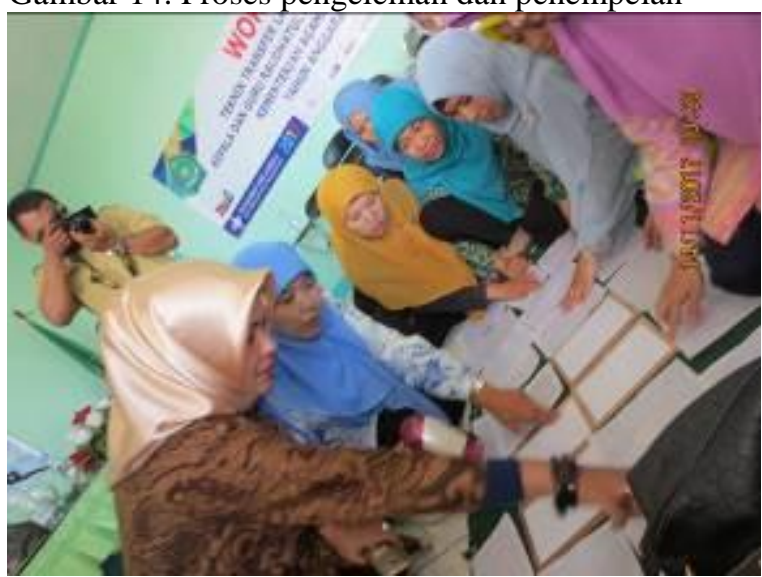

Gambar 15. Proses pengeringan 


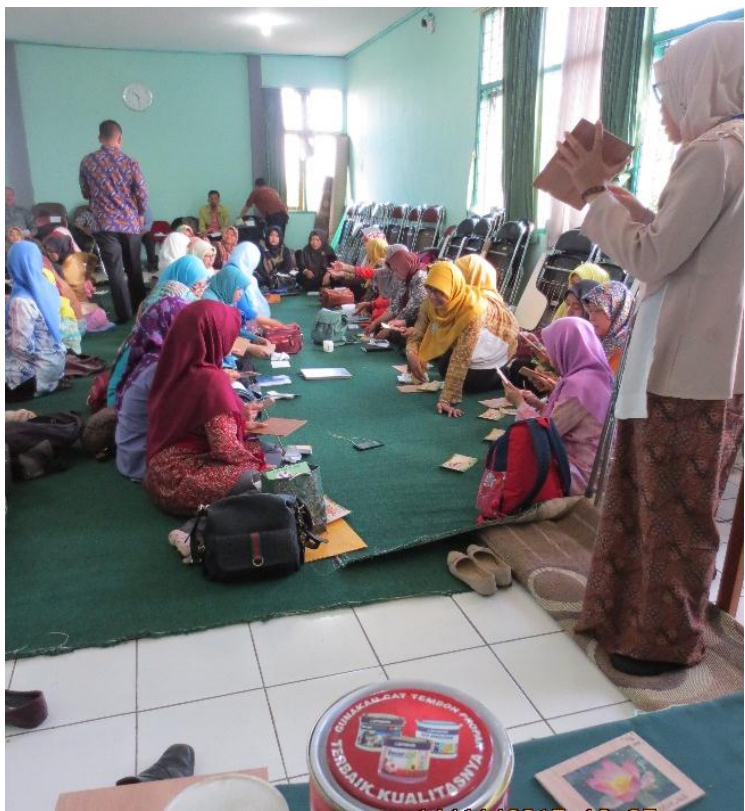

Gambar 16. Penjelasan mengenai pengangkatan kertas

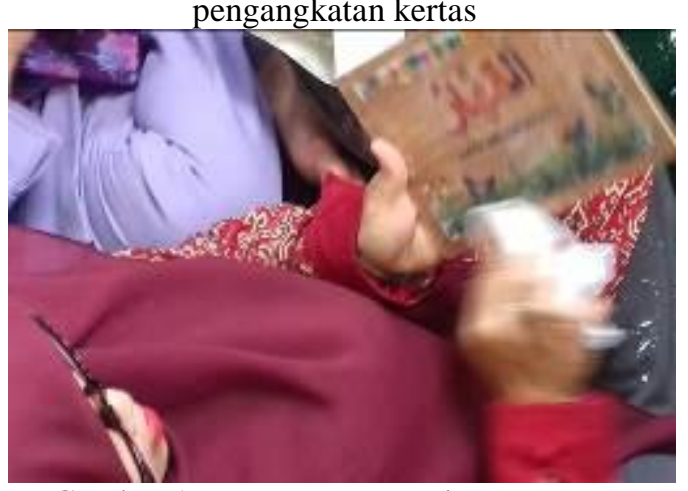

Gambar 17. Proses Pengangkatan Kertas

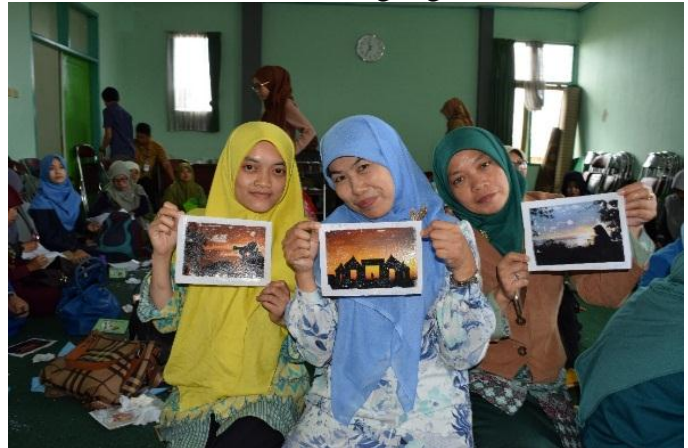

Gambar 18. Foto bersama karya

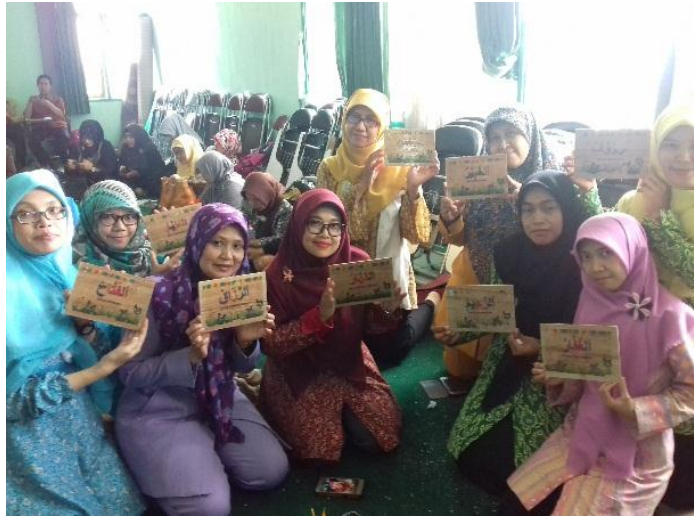

Gambar 19. Foto bersama karya

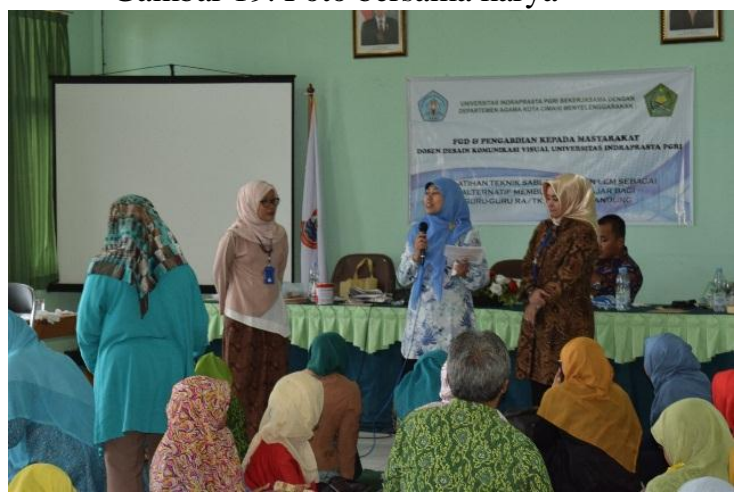

Gambar 20. Kesan dan pesan dari peserta

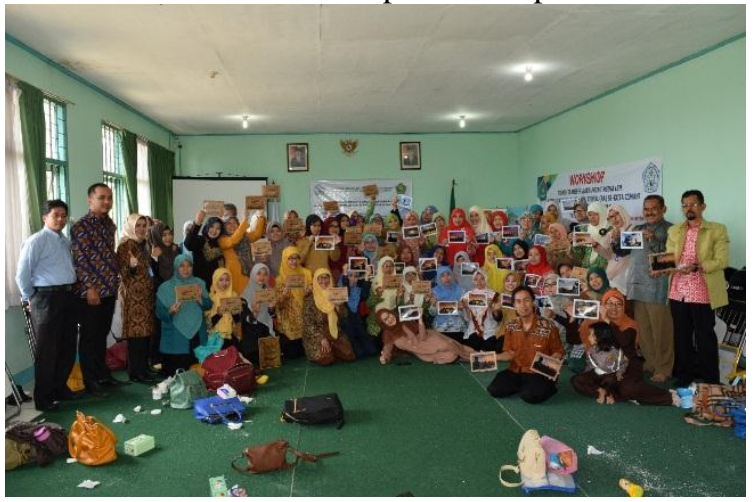

Gambar 21. Foto Bersama

Pelaksanaan kegiatan pengabdian masyarakat yang dilaksanakan oleh tim dosen DKV Universitas Indraprasta PGRI pada kesempatan kali ini telah berjalan dengan baik dan kondusif, bahkan para guru mendapatkan wawasan baru untuk mengembangkan kreativitas yang inovatif bagi mereka untuk membuat sablon dengan menggunakan screen dan cat, atau bila ingin sablon dengan media kaos bisa menggunakan kertas khusus (special paper) yang setelah diprint hanya ditekan dan proses 
pemanasan menggunakan seterika listrik ke bahan kaos dan gambar tertransfer ke media. Untuk pengabdian masyarakat selanjutnya kami menyerahkan kepada pihak Kementerian Agama Kota Cimahi yang menggoordinir sekolah-sekolah RA/TK di Kota Cimahi karena banyaknya permintaan kepada kami agar melakukan pengabdian masyarakat langsung ke sekolah-sekolah. Kami akan berusaha memenuhi permintaan itu agar kerjasama sama dan silahturahmi tetap terjalin dengan baik antara Kementerian Agama Kota Cimahi dengan Universitas Indraprasta PGRI.

\section{SIMPULAN}

Dalam kegiatan Pengabdian Masyarakat Pelatihan Teknik Sablon dengan Menggunakan Lem sebagai Alternatif membuat Bahan Ajar bagi Guru-guru RA/TK di Cimahi Bandung telah kami laksanakan dan berjalan lancar, memberikan simpulan bahwa kegiatan ini :

1. Jumlah guru sebagai peserta yang mengikuti penyuluhan dan pelatihan dalam abdimas ini dalam jumlah yang sangat cukup sehingga kami harus membagi mereka menjadi 2 kelompok, agar mudah mengerti dengan baik semua yang kami jelaskan dan kami contohkan dalam pembuatan bahan ajar ini.

2. Peserta tidak memiliki atau menyiapkan perlengkapan alat-alat pembuatan teknik yang kami ingin ajarkan, sehingga karena hanya mengandalkan bahan dan alat dari kami tim Dosen, maka mereka hanya dapat memilih contoh-contoh untuk praktik langsung sesuai dengan yang sudah kami sediakan sehingga mereka tidak dapat bereksperimen bebas sesuai keinginan mereka, dan juga pembuatan bahan ajar yang mereka lakukan masih baru sebatas teknik dasar pembuatan yang sederhana saja.

3. Penyuluhan dan pelatihan berjalan dengan baik dan seluruh peserta sangat antusias memperhatikan dan mencoba praktik langsung atas apa yang sudah kami contohkan dalam pelatihan ini.

4. Dalam praktik langsung membuat bahan ajar dengan teknik transfer laser print semua sudah berjalan dengan lancar, namun tingkat kesabaran dan ketelitian peserta yang berbeda menjadikan hasil yang mereka dapatkan ada yang bagus ada yang kurang bagus. Hasil praktik langsung peserta dalam membuat bahan ajar dari teknik yang kami sampaikan, kami persilahkan mereka untuk membawanya sebagai kenangan dari kami.

5. Tim Dosen memberikan peralatan dan perlengkapan yang masih ada kepada sekolah yang membutuhkan sebagai contoh apabila mereka ingin membelinya, dan tim siap membantu mengirimkan dari Jakarta ke sekolah-sekolah RA/TK yang membutuhkan Lem Golden karena di wilayah Bandung tidak tersedia.

\section{DAFTAR PUSTAKA}

Dameria, A. (2008). Basic Printing. Jakarta: Link \& Match Graphic. 
Direktorat Pendidikan Anak Usia Dini, Direktorat Jenderal Pendidikan Luar Sekolah Departemen Pendidikan Nasional. (2003). Alat Permainan Edukatif untuk Kelompok Bermain. Jakarta.

Montolalu. (2005). Bermain dan Permainan Anak. Jakarta: Universitas Terbuka.

Moeslichatoen, R. (2004). Metode Pengajaran di Taman Kanakkanak. Jakarta: PT. Rineka Cipta.

Munandar, S.D.U. (2009). Kreativitas dan Keberkatan. Jakarta : Rineka Cipta.

Munandar, U. (2009). Pengembangan Kreatifitas Anak Berbakat. Jakarta : Rineka Cipta.
Rustan, S. (2010). Layout Dasar dan Penerapannya. Jakarta : Gramedia Pustaka Utama.

Soetjiningsih, C.H. (2012). Perkembangan Anak: Sejak Pembuahan Sampai Dengan Kanak-Kanak Akhir. Jakarta: Prenada.

Sujiono, N. (2010). Bermain Kreatif. Jakarta: PT. Indeks.

Suwati. (2008). Sekolah Bukan Untuk mencari Pekerjaan. Jakarta: Pustaka Grafia.

https://jabar.kemenag.go.id/artikel41682-profil-kementerian-agamakota-cimahi

http://ejournal.unp.ac.id/index.php/paud /article/viewFile/1701/1470 